\title{
Research Paper: Factors Affecting Unsuccessful Suicide Among Women Referred to Emergency Room of Ardabil City Hospital, Ardabil, Iran
}

\author{
Esmaeil Farzaneh $^{1}$ Q , Firouz Amani ${ }^{2^{*}}$ Q, Fariba Sadeghi-Movahhed ${ }^{3}$ Kaveh Mataei $^{4}$ \\ 1. Department of Internal Medicine, School of Medicine, Ardabil University of Medical Science, Ardabil, Iran \\ 2. Department of Community Medicine, School of Medicine, Ardabil University of Medical Science, Ardabil, Iran. \\ 3. Department of Psychiatry, School of Medicine, Ardabil University of Medical Science, Ardabil, Iran. \\ 4. School of Medicine, Ardabil University of Medical Science, Ardabil, Iran.
}

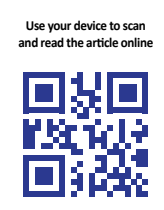

Cftation: Farzaneh E, Amani F, Sadeghi-Movahhed, Mataei K. Factors Affecting Unsuccessful Suicide Among Women Referred to Emergency Room of Ardabil City Hospital, Ardabil, Iran. International Journal of Medical Toxicology and Forensic Medicine. 2020; 10(2):27412. https://doi.org/10.32598/ijmtfm.v10i2.27412

https://doi.org/10.32598/ijmtfm.v10i2.27412

(C) 03

Article info:

Received: 09 Oct 2019

First Revision: 27 Oct 2019

Accepted: 21 Jan 2020

Published: 20 Jun 2020

\section{Keywords:}

Suicide, Psychological stress, Emotional problems, Effective factors

\section{A B STRACT}

Background: Along with the complexity of social communications, the rate of suicide is increasing, and according to studies, women commit suicide more than men. Various factors affect the occurrence of this phenomenon. The purpose of this study was to determine the factors affecting unsuccessful suicide among women referring to the emergency room of the hospital of Ardabil City, Iran.

Methods: This study was a descriptive cross-sectional study conducted on 236 women who had unsuccessful suicide. Questions were asked from patients with a checklist. This checklist has four parts. The first part relates to the patient's personal information, and the second part relates to the patient's previous history of mental, physical, and addiction problems. The third part asked about the causes of suicide and the fourth part related to the prior announcement. The collected data were analyzed by statistical methods in SPSS v. 18.

Results: The Mean \pm SD age of the women was $27.66 \pm 9.95$ years, and the majority was between 15 and 20 years old. About $64 \%$ of women were housewives, and $37.7 \%$ had undergraduate education. Also, $36 \%$ had a positive history of psychological diseases, and $30.9 \%$ had a history of suicide. The most common causes of suicide among women were emotional problems (91.9\%), family and marriage conflict (81.8\%), spouse's disregard (50.4\%), and economic issues (44.5\%).

Conclusion: The results showed that emotional problems and family and marital conflicts were common causes of suicide among women, and all women had at least one crucial reason for their suicide attempt.

\section{* Corresponding Author:}

Firouz, Amani, PhD.

Address: Department of Community Medicine, School of Medicine, Ardabil University of Medical Science, Ardabil, Iran.

Tel: +98 (45) 33534741

E-mail: firouzamani2019@gmail.com 


\section{Introduction}

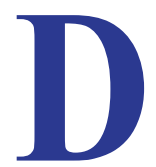

eath due to suicide occurs by the person who committed it. It is an intentional, conscious effort to terminate life. It appears to be an individual action and committed by the suicider, but social factors play a crucial role in its occurrence [1]. Psychiatric illness is a strong predictor of suicide. More than 90 percent of patients who attempt suicide have a psychiatric disorder, and $95 \%$ of patients who commited suicide have a psychiatric symptoms. Severity of psychiatric illness is associated with risk of suicide [2].

According to World Health Organization (WHO), suicide is the 13th cause of death in the world and the 3rd cause of death in the age group of 15-34 years. The rate of suicide attempts is 10-40 times more than successful suicide (leading to death), and along with the complexity of interactions and communications in all societies, the rate of suicide attempts is increasing [3]. Suicide occurs in all classes of the population, but women are more suicidal than men, but suicide leads to death in men more than women [4].

In Iran, the suicide rate is lower than most countries in the world, notably lower than Western societies, but higher than in the Middle Eastern countries [5]. According to the findings of Daliri et al study, suicide (successful and unsuccessful) can be influenced by climatic factors. Many studies in the world confirmed this hypothesis which geographical and climatic factors can affect the rate of committing suicide [6].

The WHO considers psychiatric disorders the most significant risk factor for suicide, and thus, prevention and treatment of mental disorders have an essential role in decreasing the suicide rate [7]. Studies show that suicidal methods were significantly different among men and women. The most common methods used for suicide in Iran were hanging, self-immolation, poisoning, and firearms [8]. The most commonly used method for suicide in women is drug poisoning with pills [9]. One of the ways to commit suicide is self-immolation that has a high prevalence in eastern societies compared with western ones [10]. The most common means of committing suicide among women in the western and southern provinces of the country is self-immolation [11].

A large proportion of suicide attempters referred to hospitals, and most of them are being hospitalized. The high rates of hospitalization, in addition to financial and life-threatening illnesses on the patients, make up a great deal of time and costs for the community and the treatment centers. Suicide bombers have unique characteristics, and some individual, social, material, and familial factors are presented as the risk predictors in them [12-14].

\section{Materials and Methods}

This descriptive cross-sectional study was conducted on 236 women over 15 years of age who referred to Ardabil Hospital due to unsuccessful suicide. Women's data were collected by a checklist, including demographic information, history of any mental, physical, addiction, and causes of suicide attempts. In this study, the history of child abuse has been defined by the presence of a parent or a close relative in a childhood. For studying the history of addiction, the patients were asked about the use of any industrial or synthetic drugs. The collected data were analyzed in SPSS V. 18. This study was registered at the University's Ethics Committee with the code IR.ARUMS.REC.2016.71 and written consent were taken from all participants.

\section{Results}

The Mean \pm SD age of the women was $27.66 \pm 9.89$ years. Of participants, 75 patients $(31.8 \%)$ were between 15 and 20 years old. About $69 \%$ of them were from urban and $31 \%$ from rural areas. A total of 89 women (37.7\%) had an undergraduate education, and $8.1 \%$ were illiterate. Also, 103 (43.6\%) were married, 151 (64\%) were housewives, and $16.1 \%$ were employed. The amount of monthly income in 28 people $(45.9 \%)$ of women was at a low rate. History of physical and mental illness was seen in $17 \%$ and $36.1 \%$ of women, respectively. Also, $41.5 \%$ pointed to a history of childhood violence. Around 5.1\% had a history of addiction, and $22 \%$ had an addicted partner. The most common causes of suicide among women were emotional problems with $91.9 \%$ and family and marital conflicts, with $81.8 \%$ frequency (Table 1).

Of all participants, $64 \%$ had spoken to someone about their suicide attempt. Of them, 62.3\% said that they knew about resources and support centers (police, lawyers, counseling centers, and welfare organizations). Also, 163 (69.1\%) committed suicide for the first time.

\section{Discussion}

The Mean \pm SD age of women was $27.66 \pm 9.95$ years, and the majority were between 15 and 20 years old. In Shaw's study, the majority of cases were in the age group of 15-19 years [15]. In Memari et al. study, which was 
Table 1. Causes of suicide attempts among women

\begin{tabular}{|c|c|}
\hline Causes & No. (\%) \\
\hline Husband violence & $101(42.8)$ \\
\hline Husband disregard & $119(50.4)$ \\
\hline Having suspicions & 89 (37.7) \\
\hline Prohibition of marital intercourse by the husband & $58(24.6)$ \\
\hline Prohibition of social activities by the husband & $29(12.3)$ \\
\hline Emotional problems & 217 (91.9) \\
\hline Economic problems & $105(44.5)$ \\
\hline Physical illness & $14(5.9)$ \\
\hline Mental illness (depression, etc.) & $97(41.1)$ \\
\hline Marital and family conflicts & $193(81.8)$ \\
\hline Unemployed husband & $53(22.5)$ \\
\hline Woman illiteracy & 40 (16.9) \\
\hline Husband illiteracy & $24(10.2)$ \\
\hline Lack of self-confidence & $66(28)$ \\
\hline Addiction of father, husband or other family members & $68(28.8)$ \\
\hline Divorce & $54(22.9)$ \\
\hline Educational problems & $39(16.5)$ \\
\hline
\end{tabular}

conducted on the suicide factors of married women, the average age of women was 28.7 years [16]. In Nojomi et al. study, the majority of patients were female and were in the age range of 20-24 years with an average age of 26 years [4]. In Mohebbi et al. study, the age group of 15 to 24 years was the most common age range in the study participants [17]. In Najafi et al. study, the most important motivations for suicide were psychological disorders $(60 \%)$ and then emotional problems $(22 \%)$ [18]. In Chen et al. study, the average age among suicide attempters was 33.8 years [19]. In Shaker et al. study, which was performed on 483 suicidal patients, the average age was 28 years [20].

The study found that the most common age range for those who failed suicide was 15-20 years, and this age range includes young and active members of society. As a result, the suicide attempts of these people, if accompanied by success, brings irrecoverable damage to the community. In this study, $64 \%$ of women were housewives, and $37.7 \%$ had undergraduate education. Also,
$36 \%$ had a positive history of mental illness, and $30.9 \%$ of patients had a history of suicide.

In Jangharbani et al. study, the rate of successful suicide and also suicide attempts among married people was higher than people who had never been married [21]. In Nojomi et al. study, $48 \%$ of the participants had a high school education, and $46 \%$ were housewives. Also, $3.3 \%$ had suicidal history and $30 \%$ a history of psychiatric illness [4]. In Shaker et al. study, $64.8 \%$ of the patients were single, $43.3 \%$ had undergraduate education, $32.9 \%$ were housewives, $40.7 \%$ had a history of psychiatric illness, and $22.7 \%$ had a history of suicide [20].

In the majority of studies, similar to the present study, the results showed that most people who committed suicide were married, and this is a warning that married people with family and economic problems, is a significant risk factor for occurrence suicide in communities. In this study, the leading causes of suicide attempts among women were emotional problems $(91.9 \%)$, family conflict and marital 
affairs (81.8\%), spouse disregard (50.4\%), and economic issues (44.7\%). Based on Nazarzadeh et al. study, the most common cause of suicide in the past two decades was familial conflict. Family problems with $30 \%$, marital issues with $26 \%$, and economic issues with $12 \%$ were the most important causes of suicide [12].

In Memari et al. study, the leading causes of their suicide were spouse violence with $67.7 \%$, family's humiliation with $64.6 \%$, suspicions with $38.4 \%$, neglect with $42.4 \%$, lack of social companionship and social activity with $61.6 \%$ and 5.6\%, respectively [17]. In Mohhebi study, the most common stressors were economic and financial poverty $(64.75 \%)$, attract others' attention (42.5\%), unemployment (40\%), disputes with the spouse $(32.5 \%)$, and family disputes (29.5\%) [17]. In Fathi Ashtiani et al. study, compromise problems with $19 \%$, failure in love, jealousy and distrust with $16.5 \%$, and fear of punishment with $13.7 \%$ were the most common causes of suicide among the people [22].

In the Wood et al. study, $38 \%$ of committed suicide in young people was due to non-compliance with existing conditions [23]. It was also stated that people with difficulty in communication with others have a 3-6 times increase in the risk of suicide if they also have a mental illness. In Shaker et al. study, family disputes in $48.9 \%$, psychiatric illnesses in $24.8 \%$, economic problems in $9.5 \%$, depressions, physical disease, and emotional deficiency, each with $5 \%$ were the most common causes of suicide among patients [20]. Dumais et al. also considered mental illness as one of the essential factors in suicidal phenomenon [24]. In Dadpour et al. study, most people who attempted suicide had severe depression [25].

Based on this study, the most important risk factors were personality disorders, history of suicide attempts, depression, psychosocial drugs, and lack of social support. In a meta-analysis conducted on 10258 people, the role of family, economic, social, and psychological problems have been proven in an attempt to suicide [25]. In Mohammadi et al. study, $45 \%$ of the subjects reported a history of at least one psychiatric disorder [26]. Family problem is one of the most important reasons for suicide among people, so, addressing family issues and also solving them is very important in the community.

\section{Conclusion}

The results of this study showed that emotional problems, as well as family and marital conflicts, were the most common causes of suicide among women, and all of them had at least one crucial reason for their suicide attempt. Also, most women lived in the third decade of life and were housewives. It is suggested that future studies assess the motivations for committing suicide among women.

\section{Ethical Considerations}

\section{Compliance with ethical guidelines}

This study approved by Ethical Committee of Ardabil University of Medical Science (Code IR.ARUMS REC.1395.71).

\section{Funding}

This research did not receive any specific grant from funding agencies in the public, commercial, or not-forprofit sectors.

\section{Author's contributions}

Conceptualization, writing - review \& editing: All authors; Methodology: Esmaeil Farzaneh, Firouz Amani, Kaveh Mataei; Investigation: Esmaeil Farzaneh, Fariba Sadeghi-Movahhed, Kaveh Mataei; Writing-original draft: Firouz Amani, Kaveh Mataei; Funding acquisition, resources: Esmaeil Farzaneh, Kaveh Mataei; Supervision: Esmaeil Farzaneh, Fariba Sadeghi-Movahhed.

\section{Conflict of interest}

The authors declared no conflict of interest.

\section{References}

[1] Simbar M, Golezar S, Alizadeh S, Hajifoghaha M. [Suicide risk factors in adolescents worldwide: A narrative review (Persian)]. J Rafsanjan Uni Med Sci. 2018; 16(12):1153-68. Available from: http://journal.rums.ac.ir/article-1-3851-en.pdf

[2] Schreiber J, L Culpepper. Suicidal ideation and behavior in adults [Intermet]. 2020 [Updated 2020 Apr 14]. Available form: https://www.uptodate.com/contents/suicidal-ideation-and-behavior-in-adults.

[3] Ghoreishi SA, Mousavinasab N. [Systematic review of researches on suicide and suicide attempt in Iran (Persian)]. IJPCP 2008; 14(2):115-21. Available from: http://ijpcp.iums. ac.ir/article-1-460-en.html\&sw=Systematic+Review+of+Res earches+on+Suicide+and+Suicide+Attempt+in+Iran

[4] Nojomi M, Malakouti SK, Bolhari J, Posht Mashadi M, Asghar Zadeh AS. [Predicting Factors of Suicide Attempts in Karaj General Population (Persian)]. Iran J Psychiatry Clini Psychol. 2007; 13(3):219-26. Available from: https://www. sid.ir/en/journal/ViewPaper.aspx?id=101017 
[5] Moradi S, Khademi A. Evaluation of suicides resulting in death in Iran, comparing with the World rates. Sci J Forensic Med. 2002; 8(27):16-21. Available from: https:/ / www.sid.ir/ en/journal/ViewPaper.aspx?id=74663

[6] Daliri S, Bazyar J, Sayehmiri K, Delpisheh A, Sayehmiri F. The incidence rates of suicide attempts and successful suicides in seven climatic conditions in Iran from 2001 to 2014: A systematic review and meta-analysis. SJKU. 2017; 21(6):1-15. [DOI:10.22102/21.6.1]

[7] Mowlavi P, Abbasi-Ranjbar V, Mohammad-Nia H. [Assessment of suicide risk factors among attempted suicide in $\mathrm{Ar}$ debil within first half of 1382 (Persian)]. Arch Rehabil. 2007; 8(1):67-71. [DOI:10.1186/1744-859X-7-S1-S320]

[8] You S, Van Orden KA, Conner KR. Social connections and suicidal thoughts and behavior. Psychol Addict Behav. 2011 25(1):180-4. [DOI:10.1037/a0020936] [PMID] [PMCID]

[9] Kochanek KD, Murphy SL, Anderson RN, Scott C. Deaths: Final data for 2002. Natl Vital Stat Rep. 2004; 53(5):1-5. [PMID]

[10] Solati K. [Comparison of irrational believes in suicide attempted (Self-burning) and normal individuals (Persian)]. J Shahrekord Univ Med Sci. 2000; 2(1):52-60. Available from: http://journal.skums.ac.ir/article-1-603-en.html

[11] Khazaie H, Parvizifard A. [Demographic characteristics and mental state evaluation of attempted suicide victims in Tabriz in 2001 (Persian)]. J Kermanshah Univ Med Sci. 2003; 7(3):42-51. Available from: https://www.sid.ir/en/journal/ ViewPaper.aspx?id=12873

[12] Nazarzadeh M, Bidel Z, Ayubi E, Soori H, Sayehmiri K. [Factors related to suicide attempt in Iran: A systematic review and meta-analysis (Persian)]. Hakim Health Syst Res. 2013; 15(4):352-63. Available from: https://www.magiran. com/paper/1101347?lang=en

[13] Clark D, Murray D, Ray D. Epidemiology and outcomes of patients admitted to critical care after self-poisoning. J Intensive Care Soc. 2011; 12(4):268-73. [DOI:10.1177/1751143 71101200405]

[14] Thimmaiah R, Poreddi V, Ramu R, Selvi S, Math SB. Influence of religion on attitude towards suicide: An Indian perspective. J Relig Health. 2016; 55(6):2039-52. [DOI:10.1007/ s10943-016-0213-z] [PMID]

[15] Shaw D, Fernandes JR, Rao C. Suicide in children and adolescents: A 10 Year retrospective review. Am J Forensic Med Pathol. 2005; 26(4):309-15. [DOI:10.1097/01. paf.0000188169.41158.58] [PMID]

[16] Memari A, Ramim T, Amirmoradi F, Khosravi K, Godarzi Z. [Causes of suicide in married women (Persian)]. Hayat. 2006; 12(1):47-53. Available from: http://hayat.tums.ac.ir/ article-1-218-en.pdf

[17] Mohebbi A, Boushehri B. [Stressor factors effects in intentionally committing suicide by chemical materials: Review of four hundred cases (Persian)]. Urmia Med J. 2006; 17(3):21925. Available from: https://www.sid.ir/En/Journal/ViewPaper.aspx?ID=90420

[18] Najafi F, Ahmadi Jouibari T, Moradi Nazar M, Izadi N [Causes and risk factors of self- poisoning in adolescents 15 to 20 years: A single-center study with 321 patients (Persian)]. Iran J Forensic Med. 2012; 18(1):33-8. Available from: http:/ / sjfm.ir/article-1-450-en.html
[19] Chen F, Wen JP, Wang XP, Lin Q, Lin C. Epidemiology and characteristics of acute poisoning treated at an emergency center. World J Emerg Med. 2010; 1(2):154-6. Available from: https://www.ncbi.nlm.nih.gov/pmc/articles/ PMC4129745/

[20] Shaker SH, Hosseini-Kasnaviyyeh SM, Basir-Ghafouri $\mathrm{H}$, Tavakkoli N, Yasinzadeh M, Masoumi G, et al. [Epidemiological survey of the attempted suicide patients admitted at Hazrat Rasoul Hospital in Tehran 2007-2011 (Persian)]. Iran J Forensic Med. 2017; 23(1):7-15. Available from: http://sjfm. ir/article-1-880-en.html

[21] Mohammadi S, Izadpanah Sh, Fazeli-Mehrabadi A, Panaghi L, Ghadiri F. [The effects of identity styles on suicidal thoughts among university students (Persian)]. Int J Behav Sci. 2011; 5(1):61-7. Available from: https://www.sid.ir/en/ Journal/ViewPaper.aspx?ID=206892

[22] Fathi Ashtiani A., Eslami S. H. [Evaluation of psychological pathology and causes of suicide in soldiers (Persian)]. J Mi Med. 2002; 3(4):245-9. Available from: http://militarymedj. ir/article-1-318-fa.html

[23] Wood A. Self-harm in adolescents. Adv Psychiatr Treat. 2009; 15(6):434-41. [DOI:10.1192/apt.bp.107.005348]

[24] Dumais A, Lesage A, Alda M, Rouleau G, Dumont M, Chawky N, et al. Risk factors for suicide completion in major depression: A case-control study of impulsive and aggressive behaviors in men. Am J Psychiatry. 2005; 162(11):2116-24. [DOI:10.1176/appi.ajp.162.11.2116] [PMID]

[25] Dadpour B, Madani Sani F, Rahimi Doab M, Gerami A, Rajaei P, Talebi M. Factors related in suicide attempts in admitted poisoned patients. J Patient Saf Qual Improv. 2015 3(3):247-51. Available from: http://psj.mums.ac.ir/article_4563.html

[26] Janghorbani M, Sharifirad GH. Completed and attempted suicide in Ilam, Iran (1995-2002), Incidence and associated factors. Arch Iran Med. 2005; 8(2):119-26. Available from: https:/ / www.sid.ir/en/journal/ViewPaper.aspx?ID=29789 
This Page Intentionally Left Blank 